\title{
Development and validation of Comprehensive Gait Assessment using InerTial Sensor score (C-GAITS score) derived from acceleration and angular velocity data at heel and lower trunk among community-dwelling older adults
}

Shogo Misu ${ }^{1,2^{*}}$ D, Tsuyoshi Asai ${ }^{3}$, Takehiko Doi ${ }^{4}$, Ryuichi Sawa ${ }^{2,5}$, Yuya Ueda², Shunsuke Murata ${ }^{2,6}$, Takashi Saito $^{2}$, Taiki Sugimoto $2,6,7,8$, Tsunenori $I s a^{2}$, Yamato Tsuboi ${ }^{2,5}$, Minoru Yamada ${ }^{9}$ and Rei Ono ${ }^{2}$

\begin{abstract}
Background: Although some gait parameters from inertial sensors have been shown to be associated with important clinical issues, because of controversial results, it remains uncertain which parameters for which axes are clinically valuable. Following the idea that a comprehensive score obtained by summing various gait parameters would sensitively reflect declines in gait performance, we developed a scoring method for community-dwelling older adults, the Comprehensive Gait Assessment using InerTial Sensor score (C-GAITS score). The aim of this study was to examine the internal consistency and the construct validity of this method.

Methods: In this cross-sectional study, the gait performance of 378 community-dwelling older people (mean age $=71$. $7 \pm 4.2$ years, 210 women) was assessed using inertial sensors attached to the heel and lower trunk. Participants walked along a 15-m walkway, and accelerations, angular velocity, and walking time were measured. From these data, walking speed, mean stride time, coefficients of variation of stride time and swing time, and autocorrelation coefficients and harmonic ratios of acceleration in vertical, mediolateral, and anteroposterior directions at the lower trunk were calculated. Scoring was performed based on quartile by gender (i.e., scored from 0 to 3) for each of the 10 gait parameters. The C-GAITS score was the sum of these scores (range: 0-30). Lower extremity strength, balance function, fall history, and fear of falling were also assessed.

(Continued on next page)
\end{abstract}

\footnotetext{
* Correspondence: s-misu@konan-wu.ac.jp

'Department of Physical Therapy, Faculty of Nursing and Rehabilitation, Konan Women's University, 6-2-13, Morikita-machi, Higashinada-ku, Kobe 658-0001, Japan

${ }^{2}$ Department of Community Health Sciences, Kobe University Graduate School of Health Sciences, 7-10-2 Tomogaoka, Suma-ku, Kobe 654-0142, Japan

Full list of author information is available at the end of the article
}

(c) The Author(s). 2019 Open Access This article is distributed under the terms of the Creative Commons Attribution 4.0 International License (http://creativecommons.org/licenses/by/4.0/), which permits unrestricted use, distribution, and reproduction in any medium, provided you give appropriate credit to the original author(s) and the source, provide a link to the Creative Commons license, and indicate if changes were made. The Creative Commons Public Domain Dedication waiver (http://creativecommons.org/publicdomain/zero/1.0/) applies to the data made available in this article, unless otherwise stated. 
(Continued from previous page)

Results: An exploratory factor analysis revealed that the C-GAITS score yielded four distinct factors explaining $57.1 \%$ of the variance. The Cronbach's alpha coefficient was 0.77. A single linear regression analysis showed a significant relationship between total C-GAITS score and walking speed (adjusted $R^{2}=0.28$ ). Results from bivariate comparisons using unpaired $t$-tests showed that the score was significantly related to age $(p=0.002)$, lower extremity strength ( $p=$ 0.007), balance function ( $p<0.001)$, fall history $(p=0.04)$, and fear of falling $(p<0.001)$.

Conclusions: Good internal consistency and appropriate construct validity of the C-GAITS score were confirmed among community-dwelling older adults. The score might be useful in clinical settings because of ease of use and interpretation and capability of capturing functional decline.

Keywords: Gait, Score, Validity, Inertial sensor, Acceleration, Angular velocity, Community-dwelling older people

\section{Background}

Gait is a major physical activity in daily life. Taking more steps leads to higher levels of functional health among older adults, and gait ability is thus an important factor for an independent and healthy life [1-5]. Therefore, the importance of the assessment of gait performance is widely accepted. Walking speed is the most commonly used parameter to assess gait performance and has been reported to be a predictor of functional decline and survival [2, 3]. Postural control during gait requires a complex neuromuscular system. The decline of this system with aging makes postural control a challenging task, resulting in older adults tending to have problems with gait safety and efficiency [6-10]. Thus, objective assessments of various aspects of the quality of gait movement provide a great deal of additional information about gait performance.

Inertial sensors have been proposed as a method for assessing the quality of gait movement. These are appropriate for gait assessment in clinical settings because of their low cost, small size, and durable structure [11]. Gait parameters calculated using acceleration or angular velocity data measured by inertial sensors attached to the lower extremities or trunk have been reported in many studies $[4,11,12]$. Previous studies have reported associations between these gait parameters and important clinical issues, such as aging, risk of falling, and functional declines [13-18]. Temporal parameters such as stride time or swing time represent pace of movement and balance control during gait [19]., and their variability is a marker of consistent and steady gait movement [20]. Gait parameters based on trunk movement (e.g., the regularity and smoothness of trunk acceleration) are also important, because the center of mass is in the lower trunk and the trunk plays an essential role in providing a stable platform for vision and head control [21].

Although the abovementioned gait parameters are associated with many important clinical issues, the assessment of gait using inertial sensors does not seem to have been widely applied in clinical settings. This approach is considered to have several problems from the clinical view, including a lack of clarity about which parameters for which axes are clinically valuable because past studies have yielded controversial results $[13,14,16,18,22$, 23]. Various abnormal gait patterns are exhibited by older adults because of complex postural control systems [24]. Therefore, we considered that multiple abnormal gait patterns may overlap among older adults with severe gait problems and expected that a comprehensive score obtained by summing the scores from various gait parameters would sensitively reflect declines in gait performance. In other words, the variability of abnormal gait patterns might explain the controversial results from past studies mentioned above. However, comprehensive scoring methods have not previously been reported, and the usefulness of this approach remains unclear. In addition, adequate reference data from healthy older adults are limited, especially in terms of measurements taken by inertial sensors at the trunk and lower extremities among community-dwelling older adults. Scoring based on these data will be helpful for judging whether obtained data are "good" or "bad" in clinical settings.

In this study, we developed a scoring method to comprehensively assess gait performance by incorporating and summing the scores from various gait parameters using inertial sensors among community-dwelling older adults. This scoring method is the Comprehensive Gait Assessment using InerTial Sensor score (C-GAITS score). The C-GAITS score includes assessment measures for temporal gait parameters and their variability, as well as parameters for control of trunk movement. The aim of this study was to examine the internal consistency and the construct validity of the C-GAITS score.

\section{Methods}

\section{Subjects}

This study used a cross-sectional design. We recruited 463 community-dwelling older adults through a community organization for older adults in the city of Himeji from September 2011 to December 2015. The measurements were collected annually over a period of one or 
two days, and different older adults participated in each year. The sample size was determined by how many older adults joined the organization and participated in the measurements. Eligibility criteria for this study were being over 65 years and under 85 years old (because the effects of aging on gait become significantly stronger after the age of 85 years [25].) and having the ability to walk independently without an assistive device (because walking with an assistive device significantly changes gait patterns). A total of 434 participants met both eligibility criteria. Participants were excluded if they had a self-reported history of neuromuscular disease that clearly affected gait, such as stroke or Parkinson's disease $(n=6)$. Participants with cognitive impairments assessed by a trained physical therapist were also excluded (presenting with either a Rapid Dementia Screening Test score $<7$ [26]. or a Mini Mental State Examination score $<24$ [27].; $n=42$ ). In addition, participants who did not complete our assessment of gait performance were excluded $(n=8)$. The final sample for the analysis included 378 participants. Background characteristics were assessed using a questionnaire that included questions on age, gender, and medical conditions (hypertension, diabetes mellitus, heart disease, and respiratory disease [yes/no]). Anthropometric indices (height and weight) were obtained by physical examination. Body mass index was calculated by dividing weight in kilograms by height in meters squared $\left(\mathrm{kg} / \mathrm{m}^{2}\right)$. This study was carried out in accordance with the principles of the Declaration of Helsinki. The Research Ethics Committee of Kobe Gakuin University approved the study (Approval No. HEB100806-1). Informed consent was obtained from all participants prior to participation.

\section{Gait assessment}

Participants walked along a smooth, horizontal walkway $15 \mathrm{~m}$ in length. Before the gait assessment, it was ensured that all participants were wearing appropriately sized shoes. A 10-m section of the walkway was marked with two lines positioned $2.5 \mathrm{~m}$ from either end. This was to allow for adequate space and time for acceleration and deceleration. After familiarization with the walkway, the participants were instructed to walk at a self-selected, preferred speed. An assistant walked beside the participant to prevent falls and to measure the participant's walking time in the middle $10-\mathrm{m}$ section of the walkway with a stopwatch. Walking speed was expressed in meters per second $(\mathrm{m} / \mathrm{s})$. This method has been reported to be as accurate as automated measurements [28].

Heel and trunk acceleration and angular velocity while walking were measured using two miniature, wireless inertial sensors (MVP- RF8; MicroStone, Nagano, Japan) with a sampling rate of $200 \mathrm{~Hz}$. One sensor was attached to the posterior surface of the participant's right heel with surgical tape, and the other was fixed to a belt at the level of the L3 spinous process. In this way, acceleration and angular velocity could be measured without restricting movement. All signals were synchronously and wirelessly transferred to a personal computer through a Bluetooth personal area network.

Signal processing was performed with commercially available software (MATLAB, Release 2011b; The Math Works Japan, Tokyo, Japan). Acceleration and angular velocity data were first sent through a low-pass filter with a cutoff frequency of $20 \mathrm{~Hz}$. Based on our previous work, heel-contact events were identified as vertical acceleration peaks of the heel, and toe-off events were identified as the time of the first maximum value of the sagittal angular velocity after quiet standing and every other maximum [29]. The following gait parameters were based on data acceleration and angular velocity data from five consecutive strides during steady-state walking to exclude data from the first two consecutive strides.

Mean stride time and mean swing time were computed by using heel-contact and toe-off events. Mean swing time is presented as a ratio of stride time (\% swing time), reflecting the percent of the period accounted for by the single-limb support phase, which is associated with balance control [19]. Additionally, to estimate the variability of gait, we calculated the coefficient of variation $(\mathrm{CV})$ of stride time and of swing time using the following formula: $\mathrm{CV}=$ (standard deviation/mean $) \times 100$.

To evaluate the regularity of trunk movement, acceleration data of the trunk for each direction, namely vertical (VT), mediolateral (ML), and anteroposterior (AP), were analyzed using an unbiased autocorrelation procedure that has been described elsewhere [30]. In brief, an unbiased autocorrelation coefficient (AC) is an estimate of the regularity of a time series by cross-correlation with itself at a given time shift; it is independent of the amount of data managed. A perfect replication of the gait cycle signal between neighboring strides would return an $\mathrm{AC}$ of one, and no association would yield a coefficient of zero.

The harmonic ratio (HR) was used to evaluate the control of trunk oscillation, indicating the walking smoothness during gait and step-to-step asymmetry [31, 32]. The theory behind HR and its calculation has been described previously [31]. In brief, digital Fourier transforms were performed on the acceleration signals of each stride at the trunk. The HRs in the VT and AP directions were calculated as the sum of the amplitudes of the first 10 even harmonics divided by the sum of the amplitudes of the first 10 odd harmonics. In contrast, the HR in the ML direction was calculated as the sum of the amplitudes of the odd harmonics divided by the sum of the amplitudes of the even harmonics. The means of the calculated HRs were used in the analyses. Higher HR values indicated greater walking smoothness, and lower HR values indicated less smooth movement. 
The comprehensive gait assessment using InerTial sensor (C-GAITS) score

Development of the C-GAITS score was performed using the following gait parameters:

- walking speed

- mean stride time, \% swing time

- $\mathrm{CV}$ of stride time, $\mathrm{CV}$ of swing time

- $\mathrm{AC}$ in the VT, ML, and AP directions

- $\mathrm{HR}$ in the VT, ML, and AP directions

To equalize the contribution of each gait parameter to the score, scoring was performed according to the quartile rank by gender for each gait parameter (i.e., lower than the first quartile was scored 0 , between the first quartile and the median was scored 1, between the median and the third quartile was scored 2, and higher than the third quartile was scored 3; scores ranged from 0 to 3). The C-GAITS score was calculated by summing these scores.

\section{Clinical assessments}

We administered the five-chair-stand test (5CS) and the tandem balance test (tandem test) to assess lower extremity strength and balance function, respectively. In the 5CS, participants were asked to stand up from a chair and then sit down five times as quickly as possible while keeping their arms folded across their chests. Participants who took over $11.1 \mathrm{~s}$ to complete the 5CS was classified as having impaired lower-extremity strength [33]. In the tandem test, participants were requested to hold the tandem position for $10 \mathrm{~s}$ with eyes open, and the time was measured until participants moved their feet or grasped the measurer for support, or until the $10 \mathrm{~s}$ had elapsed. Participants who held the tandem position for less than $3 \mathrm{~s}$ in the tandem test were classified as having impaired balance [33]. Fall history in the previous year and the psychological state of having a fear of falling (FoF) were also assessed using self-administered questionnaires. A fall was defined as "an event that resulted in the participant unintentionally coming to the ground or other lower level" [34]. FoF was assessed using the question "Are you afraid of falling (yes/no)?" [35].

\section{Statistical analysis}

Background characteristics and gait parameters were compared by gender using unpaired $t$-tests or $\chi^{2}$ tests.

An exploratory factor analysis for the C-GAITS score was conducted to assess the structural validity and subdomain of construct validity. The extraction method was the unweighted least squares procedure, and the number of factors was based on eigenvalues $>1$. The factors were expected to be correlated, so promax rotation used. Items that met a minimum loading of 0.5 were considered relevant, and only these gait parameters were ultimately incorporated into the C-GAITS score. According to the results of the factor analysis, each subscale score was calculated by summing the scores included in each factor.

Cronbach's alpha coefficient was used to determine the internal consistency of the C-GAITS score. The coefficient was calculated from the gait parameter scores incorporated in the C-GAITS score. An alpha coefficient of 0.70 was considered to indicate good internal reliability [36].

To further assess the construct validity, hypothesis testing was performed. A single linear regression analysis was performed between the total C-GAITS score and walking speed. Additionally, unpaired $t$-tests were performed using the total C-GAITS score and the subscale scores derived from the factor analysis as dependent variables. Age (older-old adults: age $\geq 75$ years vs. younger-old adults: age $<75$ years), lower-extremity strength, balance function, fall history, and fear of falling were used as group variables. We hypothesized that the C-GAITS score is correlated with walking speed. Additionally, the C-GAITS score was hypothesized to be associated with age, lower extremity strength, balance function, fall history, and FoF. Walking speed is a measure that represents gait function, so this measure was expected to be correlated with the other gait parameters. Theoretically, poor gait performance reflects older age, poorer lower extremity strength, and reduced balance function and leads to high falling risk and having FoF.

All statistical analyses were carried out using commercially available software (IBM SPSS statistics software, Version 20; IBM Corp., Armonk, NY, USA). The level of significance for all analyses was set at $5 \%$.

\section{Results}

The participants' characteristics and gait performance measures are summarized in Table 1 . The mean age ( \pm standard deviation [SD]) was $71.7 \pm 4.2$ years. There were 210 women $(55.6 \%)$ and 168 men (44.4\%). Compared with men, women were older $(p=0.02)$, and the women's group included more participants who had fallen in the previous year $(p=0.003)$ and more individuals with FoF $(p<0.001)$. In the gait assessment results, compared with men, women presented a significantly slower mean stride time (women: $0.95 \pm 0.07 \mathrm{~s}$, men: $1.02 \pm 0.08 \mathrm{~s}, \mathrm{p}<0.001$ ), a higher mean value of $\mathrm{AC}-\mathrm{ML}$ (women: $0.70 \pm 0.15$, men: $0.67 \pm 0.13, p=0.03$ ), a higher mean value of HR-ML (women: $2.38 \pm 0.69$, men: $2.11 \pm$ $0.60, \mathrm{p}<0.001$ ), and a higher mean value of HR-AP (women: $3.87 \pm 1.02$, men: $3.39 \pm 0.94, p<0.001$ ). No significant differences between genders were seen in walking speed (women: $1.41 \pm 0.18 \mathrm{~m} / \mathrm{s}$, men: $1.40 \pm 0.21$ $\mathrm{m} / \mathrm{s}, p=0.67$ ) or the other gait performance measures.

The reference values for the scoring of the C-GAITS based on the quartiles for each gait parameter are presented in Table 2 . The \% swing time score was excluded from the calculation of the C-GAITS score because of 
Table 1 Characterictics and gait parameters of participants by gender

\begin{tabular}{|c|c|c|c|c|}
\hline Variable & $\begin{array}{l}\text { Total } \\
(n=378)\end{array}$ & $\begin{array}{l}\text { Women } \\
(n=210,55.6 \%)\end{array}$ & $\begin{array}{l}\text { Men } \\
(n=168,44.4 \%)\end{array}$ & $p$-value \\
\hline Age (in years) & $71.7 \pm 4.2$ & $72.1 \pm 4.4$ & $71.3 \pm 3.9$ & 0.08 \\
\hline Weight (in kilograms) & $57.8 \pm 9.8$ & $52.8 \pm 7.7$ & $64.1 \pm 8.5$ & $<0.001$ \\
\hline Height (in meters) & $1.57 \pm 0.09$ & $1.51 \pm 0.05$ & $1.64 \pm 0.06$ & $<0.001$ \\
\hline Body mass index (in $\mathrm{kg} / \mathrm{m}^{2}$ ) & $23.4 \pm 2.9$ & $23.2 \pm 3.0$ & $23.7 \pm 2.8$ & 0.14 \\
\hline \multicolumn{5}{|l|}{ Medical history, n (\%) } \\
\hline Hypertension & $83(40.3)$ & $83(40.3)$ & $70(42.4)$ & 0.75 \\
\hline Diabetes & $18(8.7)$ & $18(8.7)$ & $19(11.5)$ & 0.39 \\
\hline Heart disease & $18(8.7)$ & $18(8.7)$ & $23(13.9)$ & 0.13 \\
\hline Respiratory disease & $14(6.8)$ & $14(6.8)$ & $9(5.5)$ & 0.67 \\
\hline Older-old adult (aged $\geq 75$ years), n (\%) & $96(25.4)$ & $63(30.0)$ & $33(19.6)$ & 0.02 \\
\hline Impaired lower-extremity strength ( 5 CS > 11.1 s), $n=376, \mathrm{n}(\%)$ & $43(11.4)$ & 20 (9.6) & $23(13.7)$ & 0.25 \\
\hline Impaired balance (tandem test < $3 \mathrm{~s}$ ), $n=369, \mathrm{n}(\%)$ & $38(10.3)$ & $24(11.7)$ & $14(8.5)$ & 0.39 \\
\hline Fall history in the previous year (faller), $n=377, \mathrm{n}(\%)$ & $65(17.2)$ & $47(22.5)$ & $18(10.7)$ & 0.003 \\
\hline FoF (yes), $n=372, \mathrm{n}(\%)$ & $96(25.8)$ & $78(37.7)$ & $18(10.9)$ & $<0.001$ \\
\hline Walking speed (in meters/second) & $1.40 \pm 0.20$ & $1.41 \pm 0.18$ & $1.40 \pm 0.21$ & 0.67 \\
\hline Mean stride time (in seconds) & $0.98 \pm 0.08$ & $0.95 \pm 0.07$ & $1.02 \pm 0.08$ & $<0.001$ \\
\hline$\%$ swing time & $41.9 \pm 2.3$ & $41.9 \pm 2.2$ & $41.9 \pm 2.4$ & 0.94 \\
\hline CV of stride time, $\%$ & $1.97 \pm 1.00$ & $1.97 \pm 1.03$ & $1.98 \pm 0.95$ & 0.87 \\
\hline CV of swing time, $\%$ & $3.11 \pm 1.54$ & $3.04 \pm 1.49$ & $3.20 \pm 1.60$ & 0.29 \\
\hline $\mathrm{AC}-\mathrm{VT}$ & $0.86 \pm 0.09$ & $0.86 \pm 0.10$ & $0.86 \pm 0.08$ & 0.77 \\
\hline AC-ML & $0.69 \pm 0.14$ & $0.70 \pm 0.15$ & $0.67 \pm 0.13$ & 0.03 \\
\hline AC-AP & $0.85 \pm 0.09$ & $0.86 \pm 0.10$ & $0.85 \pm 0.08$ & 0.40 \\
\hline $\mathrm{HR}-\mathrm{VT}$ & $3.37 \pm 0.87$ & $3.40 \pm 0.87$ & $3.33 \pm 0.88$ & 0.44 \\
\hline HR-ML & $2.26 \pm 0.67$ & $2.38 \pm 0.69$ & $2.11 \pm 0.60$ & $<0.001$ \\
\hline HR-AP & $3.66 \pm 1.01$ & $3.87 \pm 1.02$ & $3.39 \pm 0.94$ & $<0.001$ \\
\hline
\end{tabular}

Values are means \pm standard deviations or percentages. $P$-values were calculated using unpaired $t$-tests or $X^{2}$ tests by gender FoF: fear of falling, $5 \mathrm{CS}$ : five-chair-stand test; tandem test: tandem stand test, CV: coefficient of variation, AC: autocorrelation coefficient, VT: vertical, ML: mediolateral, AP: anteroposterior, HR: harmonic ratio

Table 2 Reference values based on quartiles for each gait parameter in the Comprehensive Gait Assessment using InerTial Sensor (C-GAITS) score

\begin{tabular}{|c|c|c|c|c|c|c|c|c|c|c|c|}
\hline & Score & Walking speed & Mean stride time & CV of stride time & CV of swing time & $A C-V T$ & AC-ML & AC-AP & HR-VT & HR-ML & HR-AP \\
\hline \multirow[t]{4}{*}{ Women } & 3 & $\geq 1.54$ & $\leq 0.89$ & $\leq 1.20$ & $\leq 1.80$ & $\geq 0.93$ & $\geq 0.82$ & $\geq 0.93$ & $\geq 3.88$ & $\geq 2.75$ & $\geq 4.37$ \\
\hline & 2 & $1.43-1.53$ & $0.90-0.93$ & $1.21-1.72$ & $1.81-2.87$ & $0.89-0.92$ & $0.72-0.81$ & $0.88-0.92$ & $3.32-3.87$ & $2.37-2.74$ & $3.76-4.36$ \\
\hline & 1 & $1.28-1.42$ & $0.94-0.98$ & $1.73-2.54$ & $2.88-3.88$ & $0.82-0.88$ & $0.61-0.71$ & $0.81-0.87$ & $2.79-3.31$ & $1.88-2.36$ & $3.16-3.75$ \\
\hline & 0 & $\leq 1.27$ & $\geq 0.99$ & $\geq 2.55$ & $\geq 3.89$ & $\leq 0.81$ & $\leq 0.60$ & $\leq 0.80$ & $\leq 2.78$ & $\leq 1.87$ & $\leq 3.15$ \\
\hline \multirow[t]{4}{*}{ Men } & 3 & $\geq 1.53$ & $\leq 0.95$ & $\leq 1.37$ & $\leq 2.00$ & $\geq 0.92$ & $\geq 0.77$ & $\geq 0.91$ & $\geq 3.85$ & $\geq 2.43$ & $\geq 3.88$ \\
\hline & 2 & $1.40-1.52$ & $0.96-1.01$ & $1.38-1.69$ & $2.01-2.89$ & $0.88-0.91$ & $0.67-0.76$ & $0.86-0.90$ & $3.16-3.84$ & $1.99-2.42$ & $3.25-3.87$ \\
\hline & 1 & $1.25-1.39$ & $1.02-1.06$ & $1.70-2.40$ & $2.90-4.20$ & $0.83-0.97$ & $0.59-0.66$ & $0.81-0.85$ & $2.69-3.15$ & $1.62-1.98$ & $2.75-3.24$ \\
\hline & 0 & $\leq 1.24$ & $\geq 1.07$ & $\geq 2.41$ & $\geq 4.21$ & $\leq 0.82$ & $\leq 0.58$ & $\leq 0.80$ & $\leq 2.68$ & $\leq 1.61$ & $\leq 2.74$ \\
\hline
\end{tabular}

CV: coefficient of variation, AC: autocorrelation coefficient, VT: vertical, ML: mediolateral, AP: anteroposterior, HR: harmonic ratio 
its low factor loading $(<0.5)$ in the exploratory factor analysis. Consequently, the remaining 10 items were selected as items for the C-GAITS score. The mean total score was $15.0 \pm 6.4$ (range: $0-30$ ).

Results of the factor analysis with promax rotation are presented in Table 3. This analysis yielded four distinct but correlated factors explaining $57.1 \%$ of the variance. The first factor accounted for $30.1 \%$ of the variance in the C-GAITS score and loaded on the AC for all directions. We labeled this factor the "regularity" factor. The second factor explained $11.3 \%$ of the variance and loaded on variables reflecting gait pace (i.e., walking speed and mean stride time) and was termed the "pace" factor. The third factor accounted for $9.9 \%$ of the variance and loaded on the CVs of stride time and swing time. We labeled this factor the "variability" factor. The fourth factor accounted for $5.9 \%$ of the variance and loaded on the HRs in all directions. We labeled this factor the "smoothness" factor. The correlation coefficients between the four subscales were above 0.20 , except for the correlation between the pace factor and the variability factor $(r=0.19$; Table 2$)$. The highest correlation was observed between the regularity factor and the variability factor $(r=0.55)$.

The internal consistency (Cronbach's alpha coefficient) of the C-GAITS score was 0.77 . The results of the single linear regression analysis between total C-GAITS score

Table 3 Factor loadings, proportion of variance, and factor correlation matrix for the 10 gait parameters included in the factor analysis

\begin{tabular}{lllll}
\hline & $\begin{array}{l}\text { Factor 1 } \\
\text { (Regularity) }\end{array}$ & $\begin{array}{l}\text { Factor 2 } \\
\text { (Pace) }\end{array}$ & $\begin{array}{l}\text { Factor 3 } \\
\text { (Variability) }\end{array}$ & $\begin{array}{l}\text { Factor 4 } \\
\text { (Smoothness) }\end{array}$ \\
\hline Walking speed & 0.01 & $\mathbf{0 . 7 9}$ & 0.01 & 0.00 \\
Mean stride time & 0.00 & $\mathbf{0 . 8 0}$ & -0.05 & 0.01 \\
CV of stride time & 0.12 & -0.06 & $\mathbf{0 . 8 1}$ & -0.06 \\
CV of swing time & -0.09 & 0.02 & $\mathbf{0 . 6 5}$ & 0.11 \\
AC-VT & $\mathbf{0 . 7 7}$ & 0.20 & 0.05 & -0.07 \\
AC-ML & $\mathbf{0 . 8 3}$ & -0.07 & -0.13 & 0.17 \\
AC-AP & $\mathbf{0 . 8 3}$ & -0.08 & 0.11 & -0.07 \\
HR-VT & 0.01 & 0.05 & 0.18 & $\mathbf{0 . 5 1}$ \\
HR-ML & 0.09 & -0.08 & -0.14 & $\mathbf{0 . 6 9}$ \\
HR-AP & -0.07 & 0.08 & 0.14 & $\mathbf{0 . 5 6}$ \\
\% of variance & 30.1 & 11.3 & 9.9 & 5.9 \\
Factor correlation & matrix & & & \\
Factor 2 & 0.29 & 1 & & 1 \\
Factor 3 & 0.53 & 0.22 & 1 & \\
Factor 4 & 0.23 & 0.21 & 0.33 &
\end{tabular}

The variables presented in boldface signify variables that loaded on each of the four factors above 0.5

$\mathrm{CV}$ : coefficient of variation, AC: autocorrelation coefficient, VT: vertical, ML: mediolateral, AP: anteroposterior, HR: harmonic ratio and walking speed are shown in Fig. 1. A higher total C-GAITS score was associated with faster walking speed (adjusted $R^{2}=0.28$ ). The significant association remained in the linear regression analysis between walking speed and total C-GAITS score when walking speed score was excluded from the calculation of the C-GAITS score. In the results from the bivariate comparisons, total C-GAITS score was significantly associated with age group (mean \pm $\mathrm{SD}=13.2 \pm 6.7$ for older-old adults vs. 15.6 \pm 6.2 for younger-old adults, $p=0.002$ ), lower extremity strength (mean $\pm \mathrm{SD}=12.5 \pm 6.5$ for those with impaired lower-extremity strength vs. $15.3 \pm 6.3$ for those with normal lower-extremity strength, $p=0.007$ ), balance function (mean $\pm \mathrm{SD}=11.7 \pm 6.5$ for those with impaired balance vs. $15.4 \pm 6.2$ for those with normal balance, $p<0.001$ ), fall history in the previous year (mean $\pm \mathrm{SD}=13.5 \pm 7.4$ for fallers vs. $15.3 \pm 6.1$ for non-fallers, $p=0.04$ ), and FoF (mean $\pm \mathrm{SD}=12.9 \pm 6.6$ for the FoF group vs. $15.7 \pm 6.2$ for the non-FoF group, $\mathrm{p}<0.001$; Table 4). Moreover, the variables associated with each of the subscales differed (Table 4). Significantly lower regularity scores were observed among those with impaired balance $(p=0.001)$, fallers $(\mathrm{p}=0.007)$, and those with FoF $(p=0.048)$. Significantly lower pace scores were seen among older-old adults $(\mathrm{p}<0.001)$, those with impaired lower-extremity strength $(p=0.01)$, those with impaired balance $(\mathrm{p}=0.04)$, and those with $\operatorname{FoF}(\mathrm{p}=0.002)$. Significantly lower variability scores were observed among older-old adults $(p=0.03)$ and those with impaired balance $(\mathrm{p}=0.04)$. Significantly lower smoothness scores were seen among older-old adults $(p=0.04)$, those with impaired lower-extremity strength $(\mathrm{p}=0.01)$, and those with FoF $(p=0.003)$.

\section{Discussion}

We developed the C-GAITS score to incorporate the scores derived from multiple gait parameters, using acceleration and angular velocity data measured with inertial sensors attached to the heel and lower trunk. An exploratory factor analysis showed that the C-GAITS score had four factors: "regularity," "pace," "variability," and "smoothness." These factors explained $57.1 \%$ of the variance. The internal consistency of the score was found to be good. A moderate correlation was observed between the score and walking speed; $28 \%$ of the variance of the score was explained by walking speed. Additionally, lower C-GAITS score was significantly associated with older age, poorer performance (impaired lower-extremity strength and balance), fall history in the previous year, and FoF. These results indicate that the C-GAITS score has appropriate construct validity (structural validity and hypothesis testing) for comprehensively assessing gait performance among community-dwelling older adults.

The strength of the current study is that it showed that the C-GAITS score, obtained by accumulating scores 


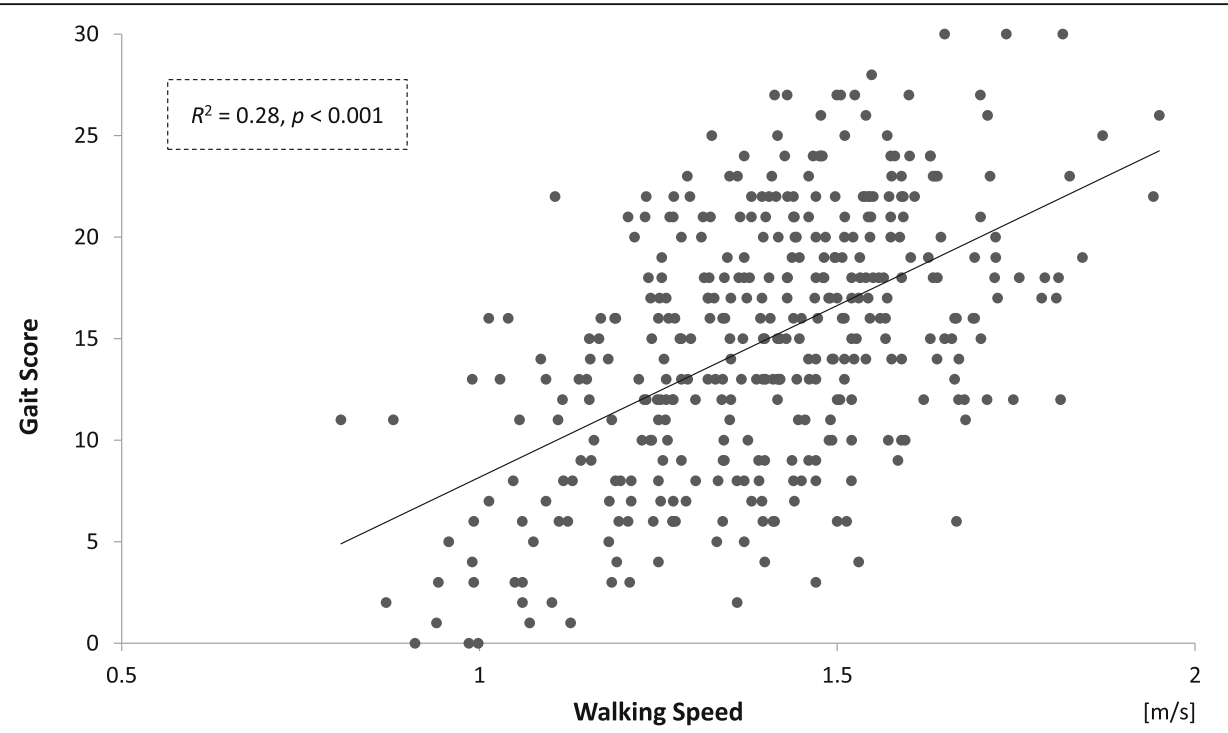

Fig. 1 Single linear regression analysis between total C-GAITS score and walking speed

derived from multiple gait parameters, had good validity for hypothesis testing. Older adults with lower physical function and higher fall risk exhibited lower C-GAITS scores, which indicated poor values for multiple gait parameters. These results are supported by previous research. Some previous studies reported that more than one gait parameter derived from trunk acceleration in all three directions was associated with lower physical function or falling risk $[13,14,37]$. For example, Moe-Nilssen et al. reported that frail older adults had lower values of $\mathrm{AC}-\mathrm{VT}, \mathrm{AC}-\mathrm{ML}$, and AC-AP, compared with fit older adults [13]., and Menz, et al. reported that older adults with high falling risk exhibited lower CVs of step time,
HR-VT, HR-ML, and HR-AP, compared with those with low risk [14]. However, the subjects in these previous studies tended to be selected using convenience sampling, and there were large differences in functional level between the groups. In contrast, other studies showed that a parameter from one direction was the only associated factor $[16-18,23,38]$. In a previous 1 -year prospective study, we found that only HR-VT predicted falling [18]. In another previous study, we found that only HR-ML was associated with FoF [16]. The samples in these studies tended to be community-based, and the differences in functional level between the groups were relatively small. Taken together, the results of the current study and the

Table 4 Associations of total C-GAITS score and subscale scores with age group, lower extremity strength, balance function, fall history, and fear of falling

\begin{tabular}{|c|c|c|c|c|c|c|c|c|c|c|}
\hline \multirow[t]{2}{*}{ Variable } & \multicolumn{2}{|l|}{ Gait score } & \multicolumn{2}{|c|}{ Regularity index } & \multicolumn{2}{|c|}{ Pace index } & \multicolumn{2}{|c|}{ Variability index } & \multicolumn{2}{|c|}{ Smoothness Index } \\
\hline & $\begin{array}{l}\text { mean } \pm \\
\mathrm{SD}\end{array}$ & $p$-value & $\begin{array}{l}\text { mean } \pm \\
\mathrm{SD}\end{array}$ & $\begin{array}{l}p_{-} \\
\text {value }\end{array}$ & $\begin{array}{l}\text { mean } \pm \\
\mathrm{SD}\end{array}$ & $p$-value & $\begin{array}{l}\text { mean } \pm \\
\text { SD }\end{array}$ & $\begin{array}{l}p- \\
\text { value }\end{array}$ & $\begin{array}{l}\text { means } \pm \\
\mathrm{SD}\end{array}$ & $\begin{array}{l}p \\
\text { value }\end{array}$ \\
\hline Older-old adult (aged $\geq 75$ years) & $13.2 \pm 6.7$ & 0.002 & $4.2 \pm 3.1$ & 0.33 & $2.3 \pm 2.0$ & $<0.001$ & $2.6 \pm 1.9$ & 0.03 & $4.0 \pm 2.5$ & 0.04 \\
\hline Younger-old adult & $15.6 \pm 6.2$ & & $4.6 \pm 2.9$ & & $3.2 \pm 2.0$ & & $3.2 \pm 2.0$ & & $4.7 \pm 2.6$ & \\
\hline $\begin{array}{l}\text { Impaired lower-extremity strength }(5 \mathrm{CS}> \\
11.1 \mathrm{~s})\end{array}$ & $12.5 \pm 6.5$ & 0.007 & $4.0 \pm 3.2$ & 0.22 & $2.3 \pm 1.8$ & 0.01 & $2.37 \pm 2.1$ & 0.35 & $3.6 \pm 2.5$ & 0.01 \\
\hline Normal lower-extremity strength & $15.3 \pm 6.3$ & & $4.5 \pm 2.9$ & & $3.1 \pm 2.0$ & & $3.0 \pm 2.0$ & & $4.6 \pm 2.5$ & \\
\hline Impaired balance (tandem test < $3.0 \mathrm{~s}$ ) & $11.7 \pm 6.5$ & $<0.001$ & $3.1 \pm 2.8$ & 0.001 & $2.4 \pm 2.2$ & 0.04 & $2.4 \pm 1.9$ & 0.04 & $3.9 \pm 2.6$ & 0.11 \\
\hline Normal balance & $15.4 \pm 6.2$ & & $4.7 \pm 2.9$ & & $3.1 \pm 2.4$ & & $3.1 \pm 2.0$ & & $4.6 \pm 2.5$ & \\
\hline Faller & $13.5 \pm 7.4$ & 0.04 & $3.6 \pm 3.0$ & 0.007 & $2.6 \pm 2.1$ & 0.08 & $3.0 \pm 1.0$ & 0.95 & $4.3 \pm 2.6$ & 0.48 \\
\hline Non-faller & $15.3 \pm 6.1$ & & $4.7 \pm 2.9$ & & $3.1 \pm 2.0$ & & $3.1 \pm 2.1$ & & $4.5 \pm 2.6$ & \\
\hline FoF & $12.9 \pm 6.6$ & $<0.001$ & $4.0 \pm 3.0$ & 0.048 & $2.4 \pm 2.1$ & 0.002 & $2.7 \pm 2.0$ & 0.07 & $3.8 \pm 2.4$ & 0.003 \\
\hline No FoF & $15.7 \pm 6.2$ & & $4.7 \pm 2.9$ & & $3.2 \pm 2.0$ & & $3.1 \pm 1.9$ & & $4.7 \pm 2.6$ & \\
\hline
\end{tabular}

$P$-values were calculated using unpaired $t$-tests

C-GAITS score: Comprehensive Gait Assessment using InerTial Sensor, 5CS: five-chair-stand test, FoF: fear of falling, SD: standard deviation, tandem test: tandem stand test 
abovementioned findings from previous work may indicate that older adults with greater functional decline exhibit low values on a larger number of gait parameters and that older adults with less functional decline exhibit low values on fewer gait parameters. Overall, these results might provide a new orientation for methods using inertial sensors in gait assessment.

In the single linear regression analysis, the total C-GAITS score was moderately correlated with walking speed $(R$-squared $=0.28)$, which is a representative marker of gait performance. This result indicates that the C-GAITS score is valid for the assessment of gait performance. However, $72 \%$ of the variance of the score was not explained by walking speed. Clinically, it is important to assess not only walking speed but also "quality of gait movement." In fact, several studies have reported that "quality of gait movement" parameters were associated with several kinds of functional declines, independent of walking speed, among older adults [16$18,39]$. The C-GAITS score includes parameters to assess regularity, variability, and smoothness, and some parts of the residual variance may be explained by these parameters. Hence, gait performance can be represented comprehensively by the C-GAITS score.

Exploratory factor analysis showed that the C-GAITS score had four factors, and each factor included the parameters from a similar calculation expression. The "regularity" factor included ACs in all three directions. AC represents the "stride-to-stride" regularity of lower trunk acceleration. The "smoothness" factor included HRs in the three directions, where HR represents the smoothness of lower trunk acceleration "within stride." The "pace" factor included spatio-temporal gait parameters in the direction of travel. The "variability" factor included the CVs of stride and swing time, which represent the stride-to-stride variability of lower extremity movement. Thus, the factor analysis results can be considered reasonable. Several previous studies reported other models of gait domains based on the results of factor analysis of computerized walkway measurements [40, 41]. Several factors similar to ours were included in their results (e.g., pace factor or variability factor). The results of the present study add value to models of gait domain because we measured not only parameters from foot movements but also parameters from trunk movements during gait. In addition, we developed subscale scores based on the factor analysis, and the each of these was related to different clinical variables. These results suggest that the subscale scores provide deeper information on gait performance and that the subscales are useful for gait assessment. It is possible that efficient intervention programs to improve gait functions could be developed using the results of factors related with each of the subscales. To clarify these factors, further studies are needed.
The C-GAITS score was calculated based on the quartiles for each gait parameter by gender, and we presented the resulting values as reference data for communitydwelling older adults. In the past, several studies have reported reference values of gait parameters using inertial sensors $[6,7,15]$, and our values were comparable but slightly higher than those found in past studies. The current study used quartile values from a large sample of older adults for scoring, and the scores were found to be significantly related to functional declines. These results suggest that our reference data provide clinically useful values for gait assessment, and data obtained in the future can be evaluated accordingly. Additionally, we presented the reference values by gender, and differences were observed between men and women on several gait parameters (stride time, AC-ML, HR-ML, and HR-AP). These parameters have previously been reported to be associated with gender $[9,42,43]$. The reference data presented in this study can thus be considered reasonable. Therefore, the C-GAITS score will be highly useful in clinical settings-not only for clinicians but also for assessment subjects-as a tool to quickly assess whether there are gait abnormalities and which gait parameters are especially low.

Several limitations should be considered in this study. First, the validation of the C-GAITS score was ascertained only for the original sample used to develop the score. Additionally, our participants are community-dwelling older adults who were able to come independently to the place where measurements were taken, suggesting that they might be well-functioning older adults (sampling bias). Further studies are warranted to confirm the external validity of the score for community-dwelling older adults, including those at various stages of health and functionality. Another limitation was that a limited number of gait parameters were used to develop the C-GAITS score, although there are many gait parameters measured using inertial sensors (e.g., root mean square, approximate entropy, Lyapunov exponents, peak amplitude variability, and symmetry index) [44-47]. In our view, examining these additional gait parameters would be a fruitful next step for future research. In the present study, we chose 10 gait parameters as the components of the C-GAITS score; we selected parameters that were commonly reported in existing studies, were easier to understand, and were simpler to calculate. Therefore, we believe that the C-GAITS score will be easily accepted in clinical fields. In addition, the gait assessment using inertial sensors was conducted only once for each subject. Although a number of past studies assessed gait performance from a single walking trial [14-18, 38, 48, 49]., several studies have reported that reliability is increased by conducting additional walking trials and calculating gait parameters from more strides. Thus, in future studies, assessing gait twice or more per 
subject or using a higher number of strides would lead to better reliability $[22,50,51]$.

\section{Conclusions}

We developed a scoring method that uses inertial sensors to comprehensively assess gait performance among community-dwelling older adults: the C-GAITS score, which incorporates the scores from various gait parameters. Good internal consistency was observed, and the appropriate construct validity of this score was confirmed by the results of an exploratory factor analysis and hypothesis testing examinations. The C-GAITS score may be useful in clinical settings because of its convenience, ease of use and interpretation, and capability of capturing functional decline among older adults.

\section{Abbreviations}

5CS: Five-chair-stand test; AC: Autocorrelation coefficient; AP: Anteroposterior; C-GAITS score: Comprehensive Gait Assessment using InerTial Sensor score; CV: Coefficient of variation; FoF: Fear of falling; HR: Harmonic ratio; ML: Mediolateral; tandem test: Tandem balance test; VT: Vertical

\section{Acknowledgments}

The authors acknowledge Dr. Soichiro Hirata and Dr. Hiroshi Ando for thei valuable advice on the conception and design of the study, as well as on gait analysis. The authors also thank the other members of Dr. Ono's laboratory at Kobe University Graduate School of Health Sciences for data acquisition and their constructive comments on the design of this study and the interpretation of the data analysis. We thank Jennifer Barrett, PhD, from Edanz Group (www.edanzediting.com/ac) for editing a draft of this manuscript.

\section{Availability of data and materia}

Data and materials are only available to members of this project. The data will not be shared with others because consent for data sharing was not obtained from the participants.

\section{Funding}

This study was supported by a Grant-in-Aid for Young Scientists (B) (22700685) from KAKENHI in Japan, and a Grant-in-Aid for Research Activity Start-up (18H06452) from KAKENHI in Japan. The role of the funding body was to prepare the inertial sensors and computers for the collection and analysis of data and to provide financial support for the data analysis.

\section{Authors' contributions}

SM has made substantial contributions to the conception and design of the study, data acquisition, and data analysis, and has been involved in drafting the manuscript. TA has made substantial contributions to the conception and design of the study, data acquisition, and data analysis, and has been involved in revising the manuscript. TD and RS have made substantial contributions to the conception and design of the study, data acquisition, data analysis, and interpretation of the data analysis. YU, SM, TS, TS, TI, and YT have made substantial contributions to the data acquisition, data analysis, and interpretation of the data analysis. MY has made substantial contributions to the conception and design of the study and data acquisition. RO has made substantial contributions to the conception and design of the study and has been involved in revising the manuscript. All authors have read and approved the final manuscript.

\section{Ethics approval and consent to participate}

This study was carried out in accordance with the principles of the Declaration of Helsinki. The Research Ethics Committee of Kobe Gakuin University approved the study (Approval No. HEB100806-1). Informed consent was obtained from all participants prior to participation.

\section{Consent for publication}

Not applicable.

\section{Competing interests}

The authors declare that they have no competing interests.

\section{Publisher's Note}

Springer Nature remains neutral with regard to jurisdictional claims in published maps and institutional affiliations.

\section{Author details}

${ }^{1}$ Department of Physical Therapy, Faculty of Nursing and Rehabilitation, Konan Women's University, 6-2-13, Morikita-machi, Higashinada-ku, Kobe 658-0001, Japan. ${ }^{2}$ Department of Community Health Sciences, Kobe University Graduate School of Health Sciences, 7-10-2 Tomogaoka, Suma-ku, Kobe 654-0142, Japan. ${ }^{3}$ Department of Physical Therapy, Faculty of Rehabilitation, Kobegakuin University, 516 Arise, Ikawadani-cho, Nishi-ku, Kobe 651-2180, Japan. ${ }^{4}$ Department of Preventive Gerontology, Center for Gerontology and Social Science, National Center for Geriatrics and Gerontology, 35 Gengo Morioka, Obu 474-8511, Japan. ${ }^{5}$ Japan Center for International Exchange, Meisan Tameike Bldg. 7F, 1-1-12 Akasaka, Minato-ku, Tokyo 107-0052, Japan. ${ }^{6} J a p a n$ Society for the Promotion of Science, Research Fellowship for Young Scientists, Kojimachi Business Center Building, 5-3-1 Kojimachi, Chiyoda-ku, Tokyo 102-0083, Japan. ${ }^{7}$ The Center for Comprehensive Care and Research on Memory Disorders, National Center for Geriatrics and Gerontology, Obu, Japan. ${ }^{8}$ Medical Genome Center, National Center for Geriatrics and Gerontology, Obu, Japan. ${ }^{9}$ Graduate School of Comprehensive Human Sciences, University of Tsukuba, Tokyo, Japan, 3-29-1 Otsuka, Bunkyo-ku, Tokyo 112-0012, Japan.

Received: 15 November 2018 Accepted: 17 May 2019

Published online: 28 May 2019

\section{References}

1. Tudor-Locke C, Craig CL, Aoyagi Y, Bell RC, Croteau KA, Bourdeaudhuij I, et al. How many steps/day are enough? For older adults and special populations. Int J Behav Nutr Phys Act. 2011;8:80.

2. Studenski S, Perera S, Patel K, Rosano C, Faulkner K, Inzitari M, et al. Gait speed and survival in older adults. JAMA. 2011;305:50-8.

3. van Kan AG, Rolland Y, Andrieu S, Bauer J, Beauchet O, Bonnefoy M, et al. Gait speed at usual pace as a predictor of adverse outcomes in communitydwelling older people an international academy on nutrition and aging (IANA) task force. J Nutr Health Aging. 2009;13:881-9.

4. Howcroft J, Kofman J, Lemaire ED. Review of fall risk assessment in geriatric populations using inertial sensors. J Neuroeng Rehabil. 2013;10:91

5. Oh B, Cho B, Choi H-C, Son K-Y, Park S, Chun S, et al. The influence of lower-extremity function in elderly individuals' quality of life (QOL): an analysis of the correlation between SPPB and EQ-5D. Arch Gerontol Geriatr. 2014:58:278-82.

6. Auvinet B, Berrut G, Touzard C, Moutel L, Collet N, Chaleil D, et al. Reference data for normal subjects obtained with an accelerometric device. Gait Posture. 2002;16:124-34.

7. Schwesig R, Leuchte S, Fischer D, Ullmann R, Kluttig A. Inertial sensor based reference gait data for healthy subjects. Gait Posture. 2011;33:673-8.

8. Brach JS, McGurl D, Wert D, Vanswearingen JM, Perera S, Cham R, et al. Validation of a measure of smoothness of walking. J Gerontol A Biol SC Med Sci. 2011;66:136-41.

9. Kobayashi H, Kakihana W, Kimura T. Combined effects of age and gender on gait symmetry and regularity assessed by autocorrelation of trunk acceleration. J Neuroeng Rehabil. 2014;11:109.

10. Kobsar D, Olson C, Paranjape R, Hadjistavropoulos T, Barden JM. Evaluation of age-related differences in the stride-to-stride fluctuations, regularity and symmetry of gait using a waist-mounted tri-axial accelerometer. Gait Posture. 2014;39:553-7.

11. Kavanagh JJ, Menz HB. Accelerometry: a technique for quantifying movement patterns during walking. Gait Posture. 2008;28:1-15.

12. Vienne A, Barrois RP, Buffat S, Ricard D, Vidal P-P. Inertial sensors to assess gait quality in patients with neurological disorders: a systematic review of technical and analytical challenges. Front Psychol. 2017;8:817.

13. Moe-Nilssen R, Helbostad JL. Interstride trunk acceleration variability but not step width variability can differentiate between fit and frail older adults. Gait Posture. 2005;21:164-70. 
14. Menz HB, Lord SR, Fitzpatrick RC. Acceleration patterns of the head and pelvis when walking are associated with risk of falling in communitydwelling older people. J Gerontol A Biol Sci Med Sci. 2003;58:M446-52.

15. Senden R, Savelberg HHCM, Grimm B, Heyligers IC, Meijer K. Accelerometrybased gait analysis, an additional objective approach to screen subjects at risk for falling. Gait Posture. 2012;36:296-300.

16. Asai T, Misu S, Sawa R, Doi T, Yamada M. The association between fear of falling and smoothness of lower trunk oscillation in gait varies according to gait speed in community-dwelling older adults. J Neuroeng Rehabil. 2017;14:5.

17. Misu S, Asai T, Doi T, Sawa R, Ueda Y, Saito T, et al. Association between gait abnormality and malnutrition in a community-dwelling elderly population. Geriatr Gerontol Int. 2017;17:1155-60.

18. Doi T, Hirata S, Ono R, Tsutsumimoto K, Misu S, Ando H. The harmonic ratio of trunk acceleration predicts falling among older people: results of a 1-year prospective study. J Neuroeng Rehabil. 2013;10:7.

19. Lincoln A. The temporal-spatial parameters. In: Kirtley C, editor. Clinical gait analysis: theory and practice. London: Churchill Livingstone; 2006. p. 15-37.

20. Hausdorff JM. Gait variability: methods, modeling and meaning. J Neuroeng Rehabil. 2005:2:19.

21. Winter D. Human balance and posture control during standing and walking. Gait Posture. 1995:3:193-214.

22. Bautmans I, Jansen B, Keymolen B, Mets T. Reliability and clinical correlates of 3D-accelerometry based gait analysis outcomes according to age and fall-risk. Gait Posture. 2011;33:366-72.

23. Weijer RHA, Hoozemans MJM, van Dieën JH. Pijnappels M. Gait Posture: Selfperceived gait stability modulates the effect of daily life gait quality on prospective falls in older adults; 2018.

24. Shumway-Cook A, Woollacott MH. Abnormal mobility. In: Motor control: translating research into clinical practice. 3rd ed. Baltimore: Lippincott Williams \& Wilkins; 2007. p. 359-89.

25. Hollman JH, de EM PRC. Normative spatiotemporal gait parameters in older adults. Gait Posture. 2011:34:111-8.

26. Kalbe E, Calabrese P, Schwalen S, Kessler J. The rapid dementia screening test (RDST): a new economical tool for detecting possible patients with dementia. Dement Geriatr Cogn Disord. 2003;16:193-9.

27. Folstein MF, Folstein SE, McHugh PR. "Mini-mental state" A practical method for grading the cognitive state of patients for the clinician. J Psychiatr Res. 1975:12:189-98.

28. Sustakoski A, Perera S, VanSwearingen JM, Studenski SA, Brach JS. The impact of testing protocol on recorded gait speed. Gait Posture. 2015;41:329-31.

29. Misu S, Asai T, Ono R, Sawa R, Tsutsumimoto K, Ando H, et al. Development and validity of methods for the estimation of temporal gait parameters from heel-attached inertial sensors in younger and older adults. Gait Posture. 2017;57:295-8

30. Moe-Nilssen R, Helbostad JL. Estimation of gait cycle characteristics by trunk accelerometry. J Biomech. 2004;37:121-6.

31. Menz HB, Lord SR, Fitzpatrick RC. Acceleration patterns of the head and pelvis when walking on level and irregular surfaces. Gait Posture. 2003;18:35-46.

32. Bellanca JL, Lowry KA, VanSwearingen JM, Brach JS. Redfern. Harmonic ratios: a quantification of step to step symmetry. J Biomech. 2013;46:828-31.

33. Guralnik J, Emonsick, Ferrucci L, Glynn R, Berkman L, Blazer D, et al. A short physical performance battery assessing lower extremity function: association with self-reported disability and prediction of mortality and nursing home admission. J Gerontol. 1994:49:M85-94.

34. Gibson M. The prevention of falls in later life. A report of the Kellogg International Work Group on the Prevention of Falls by the Elderly. Dan Med Bull. 1987;34 Suppl 4:1-24.

35. Maki B, Holliday P, Topper A. Fear of falling and postural performance in the elderly. J Gerontol. 1991;46:M123-31.

36. Bland JM, Altman DG. Statistics notes: Cronbach's alpha. BMJ. 1997;314:572.

37. van Schooten KS, Sloot LH, Bruijn SM, Kingma H, Meijer OG, Pijnappels M, et al. Sensitivity of trunk variability and stability measures to balance impairments induced by galvanic vestibular stimulation during gait. Gait Posture. 2011;33:656-60.

38. Lowry KA, Vanswearingen JM, Perera S, Studenski SA, Brach JS. Walking smoothness is associated with self-reported function after accounting for gait speed. J Gerontol A Biol Sci Med Sci. 2013;68:1286-90.

39. Sawa R, Doi T, Misu S, Saito T, Sugimoto T, Murata S, et al. The severity and number of musculoskeletal pain associated with gait in communitydwelling elderly individuals. Gait Posture. 2017;54:242-7.
40. Verghese J, Wang C, Lipton RB, Holtzer R, Xue X. Quantitative gait dysfunction and risk of cognitive decline and dementia. J Neurol Neurosurg Psychiatry. 2007;78(9):929-35

41. Lord S, Galna B, Verghese J, Coleman S, Burn D, Rochester L. Independent domains of gait in older adults and associated motor and nonmotor attributes: validation of a factor analysis approach. J Gerontol A Biol Sci Med Sci. 2013;68(7):820-7.

42. Scaglioni-Solano P, Aragón-Vargas L. Gait characteristics and sensory abilities of older adults are modulated by gender. Gait Posture. 2015;42:54-9.

43. Callisaya ML, Blizzard L, Schmidt MD, McGinley JL, kanth VK. Sex modifies the relationship between age and gait: a population-based study of older adults. J Gerontol A Biol Sci Med Sci. 2008;63:165-70.

44. Sekine M, Tamura T, Yoshida M, Suda Y, Kimura Y, Miyoshi H, et al. A gait abnormality measure based on root mean square of trunk acceleration. J Neuroeng Rehabil. 2013;10:118.

45. Kavanagh JJ, Barrett RS, Morrison S. Age-related differences in head and trunk coordination during walking. Hum Mov Sci. 2005;24:574-87.

46. Toebes M, Hoozemans M, Furrer R, Dekker J, van Dieën JH. Local dynamic stability and variability of gait are associated with fall history in elderly subjects. Gait Posture. 2012;36:527-31.

47. Hausdorff J, Hillel I, Shustak S, Din DS, Bekkers E, Pelosin E, et al. Everyday stepping quantity and quality among older adult fallers with and without mild cognitive impairment: initial evidence for new motor markers of cognitive deficits? J Gerontol a biol Sci med Sci. 2017.

48. Sawa R, Doi T, Misu S, Tsutsumimoto K, Nakakubo S, Asai T, et al. The association between fear of falling and gait variability in both leg and trunk movements. Gait Posture. 2014;40:123-7.

49. Zijlstra W. Assessment of spatio-temporal parameters during unconstrained walking. Eur J Appl Physiol. 2004;92:39-44.

50. Hartmann A, Murer K, de Bie RA, de Bruin ED. Reproducibility of spatiotemporal gait parameters under different conditions in older adults using a trunk tri-axial accelerometer system. Gait Posture. 2009;30:351-5.

51. Riva F, Bisi MC, Stagni R. Gait variability and stability measures: minimum number of strides and within-session reliability. Comput Biol Med. 2014;50:9-13.

Ready to submit your research? Choose BMC and benefit from:

- fast, convenient online submission

- thorough peer review by experienced researchers in your field

- rapid publication on acceptance

- support for research data, including large and complex data types

- gold Open Access which fosters wider collaboration and increased citations

- maximum visibility for your research: over $100 \mathrm{M}$ website views per year

At $\mathrm{BMC}$, research is always in progress.

Learn more biomedcentral.com/submissions 